\title{
Experimental Investigation of Punching Shear Behavior in RC Flat Slabs Strengthened with Micro Polypropylene Fibers
}

\author{
Mu'tasim Abdel-Jaber ${ }^{1}$, AnisShatnawi ${ }^{1}$, Khair Al-Deen Bsisu ${ }^{1}$ \\ ${ }^{1}$ Civil Engineering Department, The University of Jordan, Amman, Jordan
}

\begin{abstract}
Keywords:Reinforced Concrete, Flat Slab, Punching Shear, mid-span deflection, MicroPolypropylene Fibers.
\end{abstract}

Abstract:This research is presenting a strengthening technique for increasing punching shear resistance in reinforced concrete two way flat slabsusingdifferent concrete mix with different ratios of high performance micro polypropylene fibers as an additive.Sixteen experimental testshave been performed for the selected model. The influence of different ratios of fiber (i.e.; 6, 7.5 and 9 percent of cement weight) on the behaviorof two way solid slabs with threedifferent specifiedcompressive concrete strengths (i.e.; 20, 30 and $40 \mathrm{MPa}$ )with constant ratio of steel reinforcement has been investigated. A square $(2.5 \mathrm{~m} \times 2.5 \mathrm{~m})$ two way flat slab models subjected to concentric compression load has been chosen for such investigation.

Results obtained showed considerable increase in the punching load capacity for two way slabs when 9 per cent polypropylene fibers is used compared to medium to low effects when using lower ratios. However, using polypropylene fibers as additives have shown significant effect on deformability.

\section{Introduction:}

The reinforced concrete flat slab system is widely used as structural system. Its form-work is simple when no drop panels or column heads are required. However the nature of the failure exhibited at the connection between the slab and column is a major concern for structural designers due to the concentration of high punching shear stresses. Architects, contractors and owners avoid using flat slab system when column heads and dropped panels are required to resist punching shear stresses. Flat slab systems may prove to be more economical, saving of material and associated dead load and therefore more appealing than other flooring systems if the punching shear resistance of concrete can be enhanced.

Shear failure at slab-column connections can have disastrous consequences, as has been clearly demonstrated by some flat plate structures that have failed during construction.

Shear failure at a slab-column connection can result in progressive failures of adjacent connections of the same floor, as the load is transferred elsewhere, causing the adjacent connections to become more heavily loaded. Also, the lower floors may fail progressively as they become unable to support the impact of material dropping from above. Hence, caution is clearly needed in shear strength calculations and attention should be given to the low ductility associated with shear strength in order to avoid brittle failure conditions if possible.

Existing design procedures for shear strength, as recommended in the ACI 318 are based primarily on the results of slab-column tests. The actual behavior of the failure region of the cracked slab is extremely complex, primarily because of the combined flexural and diagonal tension crackingand the three-dimensional nature of the problem. The design provisions used are of necessity derived from empirical simplifications of the real behavior. 
The use of steel fibers in concrete improves the punching shear resistance allowing higher shear stresses to be transferred through the slab-column connection. In recent years there has been increased interest in the use of fiber-reinforced polymers (FRP) for concrete structures. As one of the new promising technologies in construction, FRP material solves the durability problem due to corrosion of steel reinforcement; hence the use of FRP fibers to replace the steel fibers in the SFRC for resistance of punching shear stresses is a new trend.

In a study by Gaston Kruger, et al (1998), six large square slabs were tested with a constant value of concrete compressive strength. Results indicated a linear diminution of the punching shear with increased eccentricity. Later results of tests were compared against six different codes in which the British Standards gave the best estimate of the punching strength with an eccentricity. Ronaldo Gomes and Paul Regan in (1999) proposed a theoretical model for analyzing the punching resistance of reinforced concrete for flat slabs with shear reinforcement of concentric loading.

Another study by Tuan Ngo (2001) carried a 29 test results taken from four different researchers consisted of circular and square slabs with a variable concrete compressive strength. Results showed that the use of high strength concrete improves the punching shear resistance allowing higher forces to be transferred through the slab-column connection. In (2004) PovilasVainiunas, et alcarried a finite element modeling analysis study showing good agreement with their eight floor slabs tested.

L. Nguyen-Minh et al (2012), studied the behavior and capacity of steel fiber reinforced concrete flat slabs under punching shear force and investigated the effect of steel fibers amount on punching shear cracking behavior and resistance of the slabs by testing twelve small scale flat slabs of different dimensions.

L.F. Maya et al (2012), presented a mechanical model for predicting the punching strength and behavior of concrete slabs with steel fibers, the proposed approach was compared to 140 slabcolumn connection tests reported in the literature, their model exhibited good agreement with the test results and properly represented the influence of steel fibers on the punching strength of FRC slab-column connections.

Fernández and Muttoni (2009), applied the critical shear crack theory to punching of reinforced concrete slabs with transverse reinforcement and concluded that the contribution of concrete to the punching shear strength of flat slabs is not constant and that the contribution of concrete to the punching shear strength is reduced for large rotations of the slab.

Cheng and Parra-Montesinos (2010), conducted a series of tests on slabs under monotonically increased concentrated load. Four different types of FRCs (or fiber reinforced mortar) and two slab tensile reinforcement ratios were evaluated. The conclusions were that the addition of fibers led to an increase in slab punching shear strength and/or deformation capacity, this increase in punching shear strength due to the use of FRC may lead to a change in failure mode from punching shear failure to flexural yielding. Test results showed that FRC only in the connection region over two slab thicknesses from each column stub face was sufficient to increase punching shear resistance in the test specimens.

\section{Research Significance and Material Properties:}

This study investigates innovative way of strengthening two way flat slabs for punching shear resistance by using high performance micro polypropylene fiber. 
Three different normal concrete mixesare used in this research in a specified compressive strength ranging from 20 to $40 \mathrm{MPa}$. Thiswill allow simulating the concrete strength in different existing reinforced concrete flat slab systems. The steel reinforcement used in this research is Grade 60 with yield strength of $420 \mathrm{MPa}$.

High performance micro polypropylene fibers meeting the requirements of ASTM C111.6 and having a tensile strength of minimum $300 \mathrm{~N} / \mathrm{m}^{2}$ were used (FOSROC - PPF) the properties of which is listed in Table 1 and shown in Figure 1.

Table 1. Mechanical properties of the micro-polypropylene fibers

\begin{tabular}{|l|l|}
\hline Form & Virgin Polypropylene fibers \\
\hline Specific gravity & $0.91 \mathrm{~g} / \mathrm{cm}^{3}$ \\
\hline Fiber thickness & 18 and 30 microns \\
\hline Young's Modulus & $5500-7000 \mathrm{MPa}$ \\
\hline Tensile Strength & $350 \mathrm{~N} / \mathrm{mm}^{2}$ \\
\hline Melting Point & $160^{\circ} \mathrm{C}$ \\
\hline Alkali content & Nil \\
\hline Sulfate content & Nil \\
\hline Air Entrainment & $\begin{array}{l}\text { Air content of concrete will not } \\
\text { be significantly increased }\end{array}$ \\
\hline
\end{tabular}

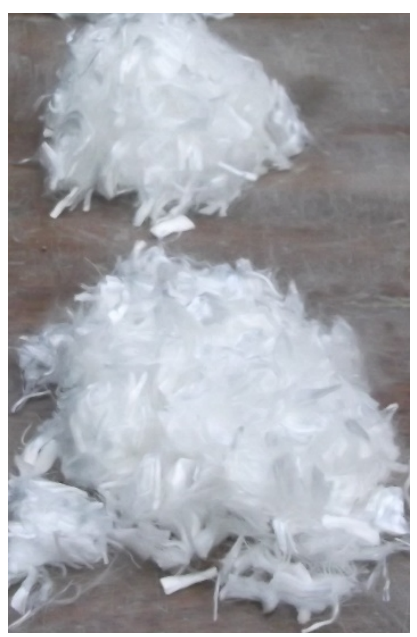

Figure 1. Micro-Polypropylene Fibers

\section{Experimental Program and Tests set-up:}

Tests were carried out in the structures laboratory of the civil engineering department at the University of Jordan. Tests were performed with a total number of 16 full-scaled reinforced concrete flat slabs with a square concrete column in the middle of the slab to assure concentric loading case. The slabs were assumed to resist shear loads by concrete only with no contribution from any shear reinforcement.

Samples were tested up to punching failure with constant ratio of steel for three different compressive concrete strength values ( 20,30 and $40 \mathrm{MPa}$ ) investigating the influence of different ratios of fiber on the behavior of the slabs.

Figures 2 and 3, shows thespecimen details. The slabs are square inshape $(2.5 \mathrm{~m} \times 2.5 \mathrm{~m})$ with a total thickness of $0.15 \mathrm{~m}$, carrying a squared column of $(0.25 \times 0.25 \mathrm{~m})$ located at the centre of the slab. Same dimensions have been used for all test samples. All slabs were constructed with a simply supporting restraints achieved by knife edges laid on steel beams. 


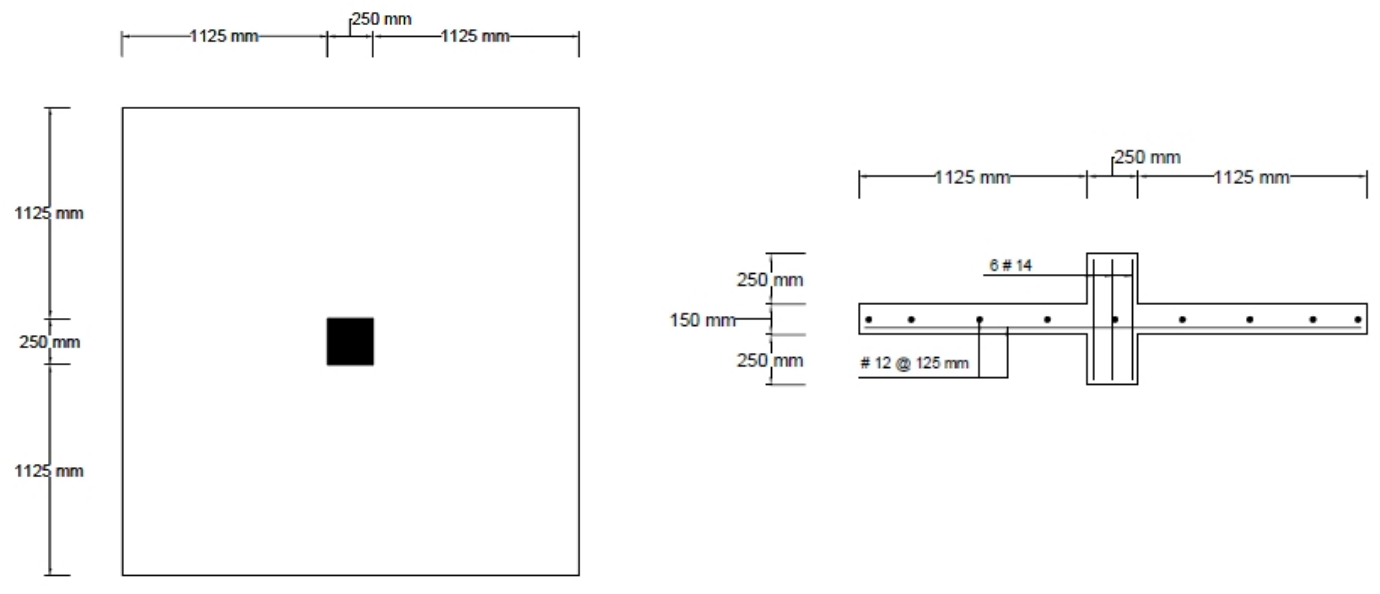

Figure 2.Specimen details

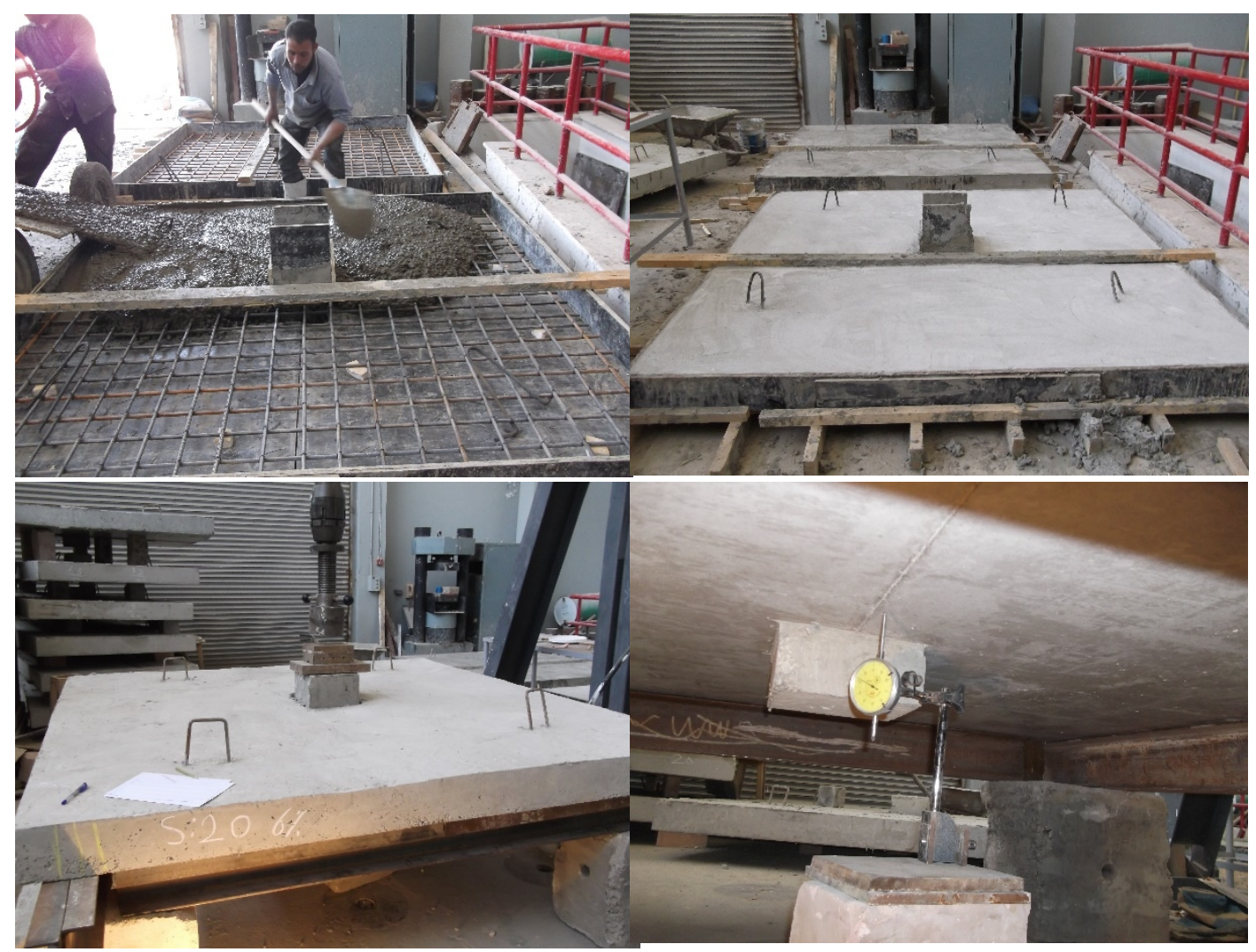

Figure 3. Specimen Casting and Test Setup

\section{Loading Procedure and Measurements:}

The tests were performed with a deformation controlled hydraulic jack with an ultimate capacity of $650 \mathrm{kN}$ applying a compressive load with a constant loading rate of $5 \mathrm{kN}$ per minute. During every experiment, the load was applied in steps of $25 \mathrm{kN}$ at which between loading steps the load was kept constant for 10 minutes to allow measurements and observations. Load was measured against midspan deflection.

After maximum load was achieved, the deformation was further increased to record the punching behavior of the slab.

The deflection and the ultimate load for each step were recordedin every experiment; and results of load-deflection relationship were plotted. 


\section{Results and Conclusions}

The concrete cylinders were tested for tensile strength as shown in Figure. 4, the tensile strength of concrete showed an increase of about $10 \%$ to $12 \%$ as tabulated in Table 2 . In each test the midspan deflection at each step and the ultimate load were recorded, results were plotted in Figures 5, 6 and 7.

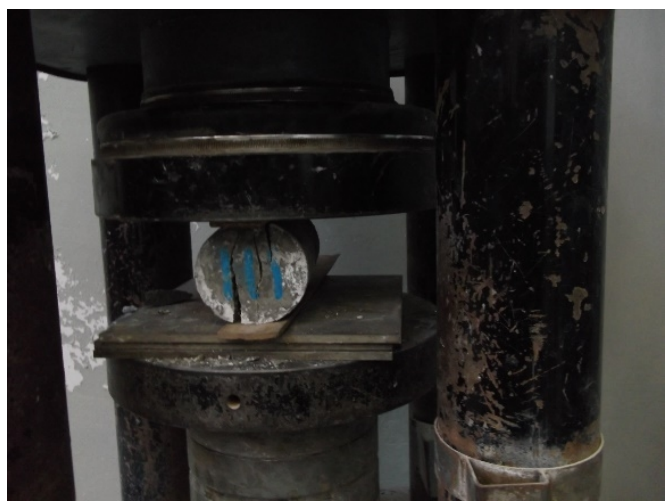

Figure. 4. Tensile (splitting) test

Table 2. Tensile Strength of Concrete with Micro-Polypropylene Fibers

\begin{tabular}{|c|c|c|c|}
\hline $\begin{array}{c}\text { Concrete Nominal } \\
\text { Compressive } \\
\begin{array}{c}\text { Strength } \\
f_{\mathrm{c}}^{\prime}(\mathrm{MPa})\end{array}\end{array}$ & $\begin{array}{c}\text { Concrete } \\
\text { Experimental } \\
\text { Tensile Strength } \\
f_{\mathrm{c}}^{\prime}(\mathrm{MPa})\end{array}$ & $\begin{array}{c}\text { Micro-Polypropylene } \\
\text { Fiber Content \% }\end{array}$ & $\begin{array}{c}\text { Concrete } \\
\text { Experimental } \\
\text { Tensile Strength } \\
f_{\mathrm{r}}^{\prime}(\mathrm{MPa})\end{array}$ \\
\hline 20 & 20.6 & 6 & 3.05 \\
\hline & 19.8 & 9.5 & 3.32 \\
\hline & 20.2 & 6 & 3.61 \\
\hline & 29.25 & 7.5 & 3.75 \\
\hline & 29.8 & 9 & 3.88 \\
\hline & 30.6 & 6 & 3.96 \\
\hline & 40.2 & 7.5 & 4.35 \\
\hline & 39.7 & 9 & 4.42 \\
\hline & 40.5 & & 4.51 \\
\hline
\end{tabular}

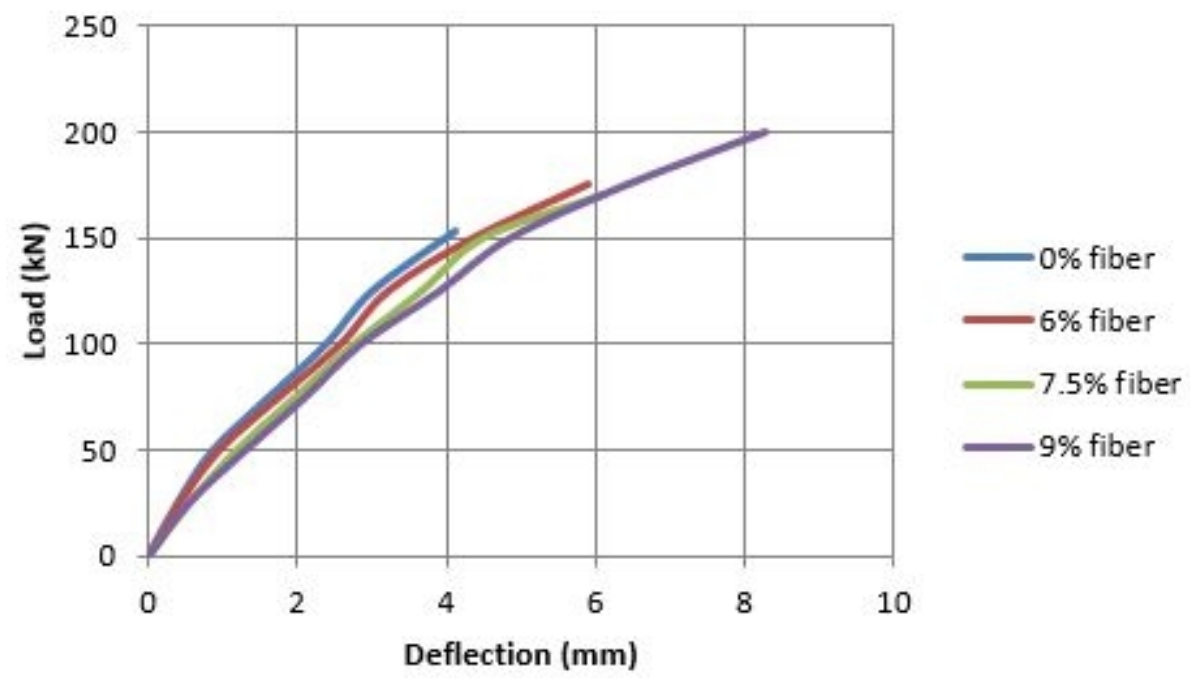

Figure 5. Load VS Deflection for $f_{\mathrm{c}}^{\prime}=20 \mathrm{MPa}$ 


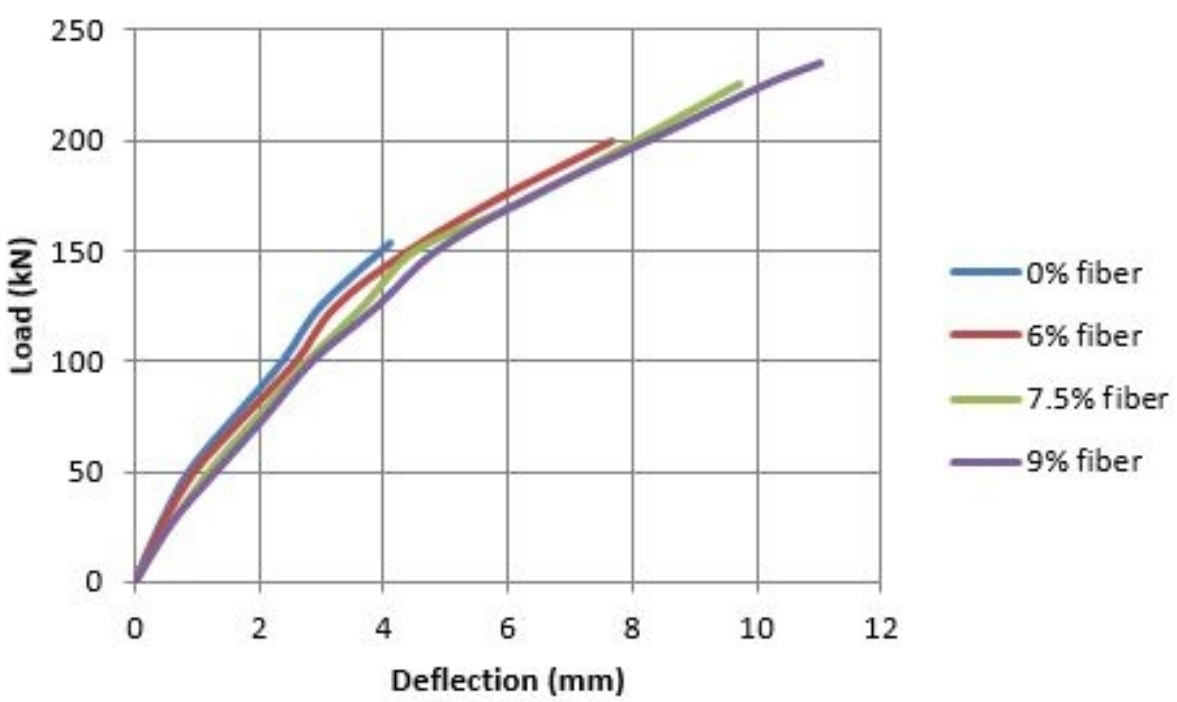

Figure 6. Load VS Deflection for $f_{\mathrm{c}}^{\prime}=30 \mathrm{MPa}$

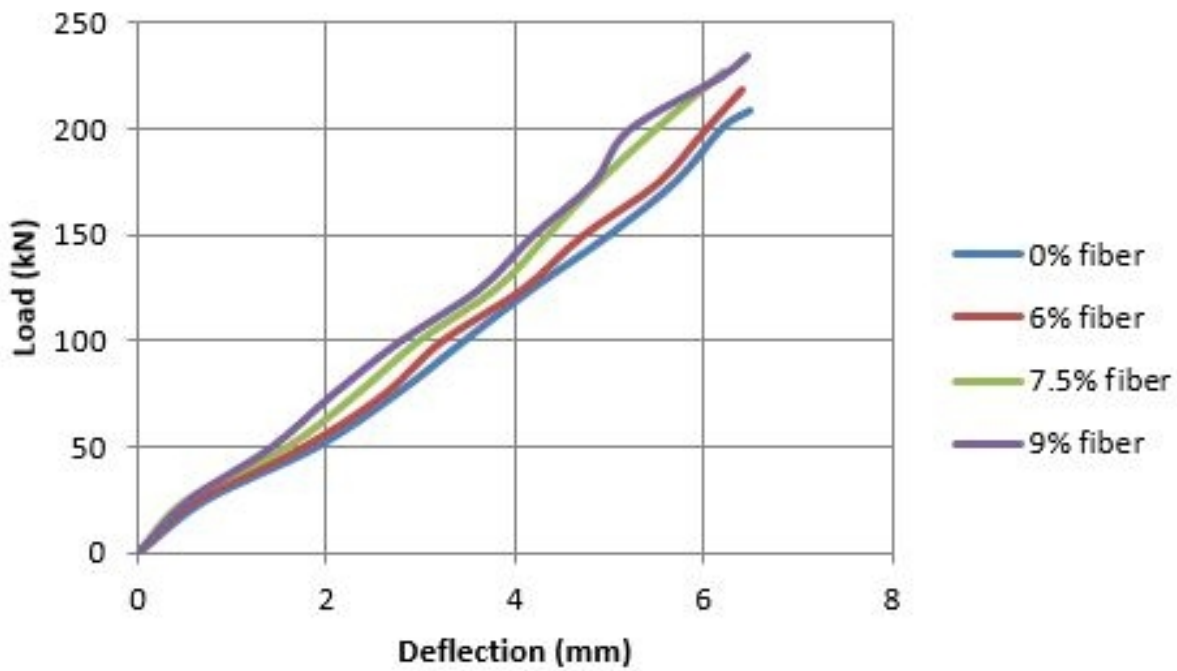

Figure 7. Load VS Deflection for $f_{\mathrm{c}}^{\prime}=40 \mathrm{MPa}$

From Figures. 5,6 and 7 it is obvious that using micro-polypropylene fibers will increase the punching shear resistance of the flat reinforced concrete slabs with $f_{\mathrm{c}}$ ' $=20 \mathrm{MPa}$ and $30 \mathrm{MPa}$ by approximately $15 \%$ while the deflection at failure has increased by approximately $25 \%$. However the flat slabs made with concrete $f_{\mathrm{c}}{ }^{\prime}=40 \mathrm{MPa}$ showed increase in total load of approximately $12 \%$ and no increase in the deflection at failure.

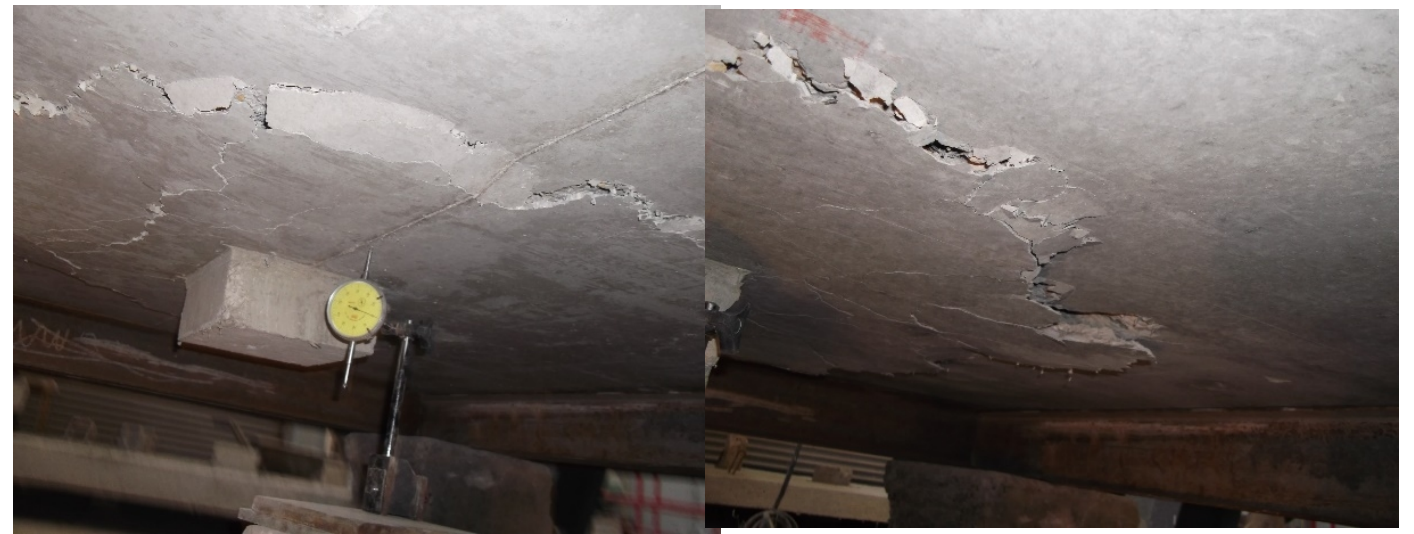

Figure 8. Failure pattern of specimens 
From this result it is understood that the punching shear resistance and deflection at failure of flat slabs using concrete with $f_{\mathrm{c}}$ ' $\leq 30 \mathrm{MPa}$ is enhanced when using the micro-polypropylene fibers with different ratioswhile the flat slab made using concrete with $f_{\mathrm{c}}{ }^{\prime} \geq 30 \mathrm{MPa}$ and micro-polypropylene fibers will only enhance the shear resistance but will not increase the deflection at failure.This means that the tensile strength of the concrete has been enhanced, i.e. the fibers will resist more tensile forces in the shear zone.

All the tested specimens showed punching-shear failure as the final mode of failure with similar crack patterns, regardless the percentage of the micro polypropylene fibersas could be noticed in Figure. 8.

\section{Acknowledgments}

The authors would like to thank the deanship of academic research in The University of Jordan for their financial support to perform this research.

\section{References}

[1] ACI 318-2005, Building Code Requirement for Reinforced Concrete. American Concrete Institute, Detroit.

[2] BS 8110-2002, Code of the Practice for Design and Construction. British Standards, Structural use of Concrete, Part 1.

[3] Cheng. Y, Gustavo J. Parra-Montesinos. Evaluation of Steel Fiber Reinforcement for Punching Shear Resistance in Slab-Column Connections- Part I: Monotonically Increased Load. ACI Structural Journal. Feb 2010. Pp. 101-109.

[4] D. Tuan Ngo, Punching Shear Resistance of High-Strength Concrete Slabs. Electronic Journal of Structural Engineering, 1, 2001, pp 52-59.

[5] Fernández Ruiz M., Muttoni A. Applications of the Critical Shear Crack theory to punching of R/C Slabs with transverse reinforcement. ACI Structural Journal, Vol. 10, 6 No. 4. 2009, pp. 485-495.

[6] Gaston Kruger, Olivier Burdet and Renaud Favre, Punching Tests on RC Flat Slabs with Eccentric loading. $2^{\text {nd }}$ IntPh.D Symposium in Civil Engineering 1998, Budapest.

[7] Ibrahim M. Metwalyy, Mohamed S. Issa and Sameh A. El-Betar. Punching Shear Resistance of Normal and High Strength Reinforced Concrete Flat Slabs. Civil Engineering Research magazine. Vol. 30, No. 3. Oct. 2008, pp 983-1004.

[8] Long Nguyen-Minh, Marian Rovnak and Toan Tran Quoc. Punching Shear Capacity of Interior SFRC Slab Column Connections. Journal of Structural Engineering, Vol. 138, Issue 5 May 2012.

[9] Marzouk, H., and Hussein, A.,Experimental Investigation on the Behavior of

[10]High-Strength Concrete Slabs, ACI Structural Journal, Vol. 88, No. 6, Nov.-

[11]Dec. 1991, pp. 701-713.

[12] Maya Duque, Fernandez Ruiz, M. Muttoni and Foster S. J. Punching Shear Strength of Steel Fiber Reinforced Concrete Slabs. Engineering Structures, Vol. 40, UK 2012, pp.93-94.

[13]M. Cheng and Parra-Montesions. Evaluation of Steel fiber Reinforcement for punching Shear Resistance in Slab-Column Connections. ACI Structural journal, 107-1. Jan 2010, pp 101-109.

[14]Nobari, H. F. and Ejlaly, R.,Punching Shear Resistance of High-Strength

[15] Concrete Slabs. Asian Journal of Civil Engineering,Building and Housing, 
[16]Vol. 4, No. 1, 2003, pp. 55-63.

[17]PovilasVainiunas, VladimirasPopovas and Andrej Jarmolajev, Non Linear FEM Analysis of RC Floor Slab-to-Column Joint Connection. Theoritical Foundation of Civil Engineering, Warsaw 2004, pp 527-538.

[18]Ronaldo B. Gomes and Paul E. Regan, Punching Resistance of RC Flat Slabs with Shear Reinforcement. Journal of Structural Engineering, June 1999, pp 684-692. 